\title{
DRUG UTILISATION TRENDS IN ENT OUTPATIENT DEPARTMENT IN A TERTIARY CARE HOSPITAL OF SIKKIM
}

Santosh Prasad Kesari ${ }^{1}$, Sunil Kumar Pandey², Sridutt Shekhar 3 , Surbhi Singhal ${ }^{4}$

${ }^{1}$ Assistant Professor, Department of ENT, Sikkim Manipal Institute of Medical Sciences, Gangtok, Sikkim.

${ }^{2}$ Associate Professor, Department of Pharmacology, Gayatri Vidya Parishad Institute of Health Care and Medical Technology,

Vishakapatnam, Andhra Pradesh.

${ }^{3}$ MS Postgraduate Trainee, Department of ENT, Sikkim Manipal Institute of Medical Sciences, Gangtok, Sikkim.

${ }^{4}$ MBBS Student, Department of ENT, Sikkim Manipal Institute of Medical Sciences, Gangtok, Sikkim.

\section{ABSTRACT}

\section{BACKGROUND}

Drug utilisation study is a powerful exploratory tool to evaluate the prescription pattern of various drugs for different diseases. Inappropriate drug use may lead to increased effect and patient mortality. The study is conducted with an aim of generating up-todate information of the drug use in ENT OPD and compare the prescribing practice with the standard.

\section{MATERIALS AND METHODS}

A total of 600 prescriptions were studied. The OPD prescription slips and patient's case sheets were screened during the study period for the details such as the demographic profile, economic status, diagnosis and treatment received.

\section{RESULTS}

A total of 1614 drugs were prescribed in 600 prescriptions at an average of 2.69 drugs per prescription, the commonest antibiotic prescribed was penicillin group.

\section{CONCLUSION}

The result of the study sets a platform for the future researchers to add to the existing knowledge.

\section{KEYWORDS}

Sikkim, Prescription Pattern, ENT, Utilisation Hospital Study.

HOW TO CITE THIS ARTICLE: Kesari SP, Pandey SK, Shekhar S, et al. Drug utilisation trends in ENT outpatient department in a tertiary care hospital of Sikkim. J. Evolution Med. Dent. Sci. 2017;6(87):6047-6055, DOI: 10.14260/jemds/2017/1314

\section{BACKGROUND}

Drug plays an important role in improving health and promotes well-being, so to produce the desired effects it has to be prescribed rationally and safely. Usage of the drug is a complex process; an optimal benefit of drug therapy in patient care may not be reached because of underuse, overuse or misuse of a drug. In any country, a large number of socio-cultural factors affect the way drugs are used. ${ }^{1}$ The pattern of use can explain the extent and profile of drug used and its frequency, quality of use audits, contrasting the use of drugs with national, local and regional guidelines or formularies.

Drug utilisation study is a powerful exploratory tool to evaluate the prescription pattern of various drugs for different diseases. Drug Utilisation Study is defined as "marketing, distribution, prescription and use of drugs in a society with special stress on medical, social and economic consequences."2,3 These studies focus on the factors related to the prescribing, disbursing, administering and intake of medication. ${ }^{4}$ Inappropriate drug use may lead to increased

'Financial or Other Competing Interest': Dr. Kesari reports grants from ICMR, New Delhi, during the conduct of the study.

Submission 20-09-2017, Peer Review 19-10-2017,

Acceptance 24-10-2017, Published 30-10-2017.

Corresponding Author:

Dr. Santosh Prasad Kesari,

Assistant Professor,

Department of ENT,

Central Referral Hospital,

SMIMS, $5^{\text {th }}$ Mile, Tadong, Gangtok.

E-mail: santosh4uma@yahoo.co.in

DOI: $10.14260 /$ jemds $/ 2017 / 1314$ effect and patient mortality. Hence, in the recent years, drug utilisation studies have become an important tool to evaluate a health care system. ${ }^{3}$

Acute respiratory infections (ARIs) account for 20\% $40 \%$ of outpatient and $12 \%-35 \%$ of inpatient records in a general hospital. ${ }^{3}$ URTIs including otitis media mainly constitutes $87.5 \%$ of the overall episodes of respiratory infections and are a major source of morbidity and absenteeism at work. ${ }^{3}$ The study of prescribing pattern infers to monitor, evaluate and suggest changes in the practitioner's prescription habits, so that patient's care can be reasonable and effective. ${ }^{5}$

The aim of the study is to generate up-to-date information on drugs used in ENT department, as no such study has been done for ENT diseases in this part of the country. It would encourage good evidence based practice and facilitate proper use of drugs.

\section{Aims and Objectives}

1. To generate up-to-date information of drug use in ENT OPD.

2. To evaluate and compare the patterns of drug prescribing practice with the standard protocol.

\section{MATERIALS AND METHODS \\ Study Type}

Hospital based cross-sectional observational study. 


\section{Study Setting}

The present study was conducted in the Department of ENT and Head and Neck Surgery, Central Referral Hospital, Sikkim Manipal Institute of Medical Sciences, 5th Mile, Tadong, Gangtok, Sikkim and STNM Hospital, Gangtok, Sikkim.

\section{Study Period}

Two months period.

\section{Sample Size}

Because of the exploratory nature of the study and time constraint, the total number of prescriptions included in our study was six hundred (600).

\section{Definition of Case}

Patients who reported to ENT OPD with common ENT diseases without co-morbid diseases were included.

\section{Sampling Technique}

Simple random sampling method was applied to select the cases for the study.

\section{Data Collection}

After obtaining the written informed consent from the patient diagnosed with the common ENT problems without any comorbid conditions and receiving the medication, presenting to ENT outpatient department of the Central Referral Hospital and STNM Hospital, Gangtok. He/ She will be questioned regarding their socio-demographic profile. The OPD prescription slips and patient's case sheets will be screened during the study period for the details such as the disease. The patient is suffering from the medication he/she is on. The patients were asked to feel free to withdraw from the study whenever he/she wishes.

\author{
The following Data will be noted down in the Case Record \\ form \\ - Patient's particulars. \\ - Symptoms. \\ - Investigation. \\ - Treatment. \\ - Condition of disease.
}

Subsequently, a detailed profile of each patient was made in terms of demographic characteristics with common ENT problems like Otitis Externa, Otomycosis, Chronic Suppurative Otitis Media (CSOM), ASOM (Acute Suppurative Otitis Media), Secretory Otitis Media (SOM), Tonsillitis, Pharyngitis, Sinusitis, Nasal Polyposis and Rhinitis of acute onset without co-morbid condition. The different groups of drugs prescribed in different subgroups was noted and the raw data was analysed and interpreted for meaningful results.

\section{Inclusion Criteria}

- Agree to give a voluntary consent.

- Suffer from common ENT diseases without co-morbid condition.

\section{Exclusion Criteria}

- Person who denies to give a voluntary consent.
- Person who is on the medication of other co-morbid diseases.

\section{Data Analysis}

The data obtained was sorted and categorised on the basis of demographic characteristics (Gender and Age), diagnosis, number of drugs prescribed and classes of drugs. The information was compiled and analysed by running frequency and chi-square analysis using SPSS version 16.00 . The $\mathrm{p}<0.05$ was considered significant.

\section{Ethical Consideration}

The institutional ethical clearance was obtained prior to start of the study.

\section{RESULTS}

\begin{tabular}{|c|c|c|}
\hline $\begin{array}{c}\text { Socio- } \\
\text { Demographic } \\
\text { Variables }\end{array}$ & $\begin{array}{c}\text { Total Studied } \\
\text { Population and } \\
\text { Prescriptions } \\
(\mathrm{N}=600) \\
\end{array}$ & $\begin{array}{c}\text { Percentage } \\
\text { (\%) }\end{array}$ \\
\hline \multicolumn{3}{|c|}{ Gender } \\
\hline Male & 274 & 45.7 \\
\hline Female & 326 & 54.3 \\
\hline \multicolumn{3}{|c|}{ Age Group (yrs.) } \\
\hline$\leq 20$ years & 180 & 30.0 \\
\hline 21- 40 years & 295 & 49.2 \\
\hline $41-60$ years & 103 & 17.2 \\
\hline$>60$ years & 022 & 3.60 \\
\hline \multicolumn{3}{|c|}{ Religion } \\
\hline Hindu & 383 & 63.8 \\
\hline Buddhist & 168 & 28.0 \\
\hline Christian & 044 & 7.30 \\
\hline Muslim & 004 & 0.70 \\
\hline Sikh & 001 & 0.20 \\
\hline \multicolumn{3}{|c|}{ Community } \\
\hline Nepali & 229 & 38.2 \\
\hline Bhutia & 052 & 8.60 \\
\hline Lepcha & 018 & 3.00 \\
\hline Others & 301 & 50.2 \\
\hline \multicolumn{3}{|c|}{ Address } \\
\hline East Sikkim & 559 & 93.2 \\
\hline West Sikkim & 017 & 2.80 \\
\hline South Sikkim & 016 & 2.70 \\
\hline North Sikkim & 008 & 1.30 \\
\hline \multicolumn{3}{|c|}{ Marital Status } \\
\hline Married & 284 & 47.3 \\
\hline Unmarried & 290 & 48.3 \\
\hline Widow/ Widower & 026 & 4.40 \\
\hline \multicolumn{3}{|c|}{ Literacy } \\
\hline Illiterate & 120 & 20.0 \\
\hline School Dropout & 159 & 26.5 \\
\hline Secondary School & 055 & 9.20 \\
\hline Post High School & 137 & 22.8 \\
\hline Bachelor and PG & 129 & 21.5 \\
\hline \multicolumn{3}{|c|}{ Socioeconomic Status } \\
\hline Upper Class & 184 & 30.7 \\
\hline Upper Middle Class & 187 & 31.2 \\
\hline Lower Middle Class & 123 & 20.5 \\
\hline Upper Lower Class & 074 & 12.3 \\
\hline Lower Class & 032 & 5.30 \\
\hline
\end{tabular}




\begin{tabular}{|c|c|c|}
\hline \multicolumn{3}{|c|}{ Site Specific Complaint } \\
\hline Ear & 192 & 32.0 \\
\hline Nose & 120 & 20.0 \\
\hline Throat & 218 & 36.3 \\
\hline Others & 070 & 11.7 \\
\hline \multicolumn{2}{|c|}{ Duration of Complaint } \\
\hline < 1 week & 396 & 66.0 \\
\hline 1-2 weeks & $\mathbf{1 1 9}$ & $\mathbf{1 9 . 8}$ \\
\hline > 2 weeks & 085 & 14.2 \\
\hline
\end{tabular}

Table 1. Baseline Characteristics of the Population Studied

Table 1 shows the baseline characteristics of the study population where a total of 600 individuals are studied, of which $274(45.7 \%)$ are male and $326(54.3 \%)$ are female, majority of the population belong to age group of 21 - 40 years, which accounts for 295 (49.2\%). Among the study groups 383 (63.8\%) belonged to Hindu religion followed by Buddhist (28\%) and Christians (7.3\%). Community wise, Nepali community accounted for $38.2 \%$ and others which consists mainly of Bengali, Bihari and Marwari together make $50.2 \%$ of the population. Majority of study population come from the east district, which account for $93.2 \%$ of the study population; $47.3 \%$ of the study population are married and $48.3 \%$ are unmarried. On analysis of literacy rate of the study population, we found that majority of them are literate with minimum of primary formal education and majority belonging to middle class family. Amongst the study population $32 \%$ presented with ear complaint, $36.3 \%$ presented with throat complaint and only $20 \%$ came with nasal complaint.

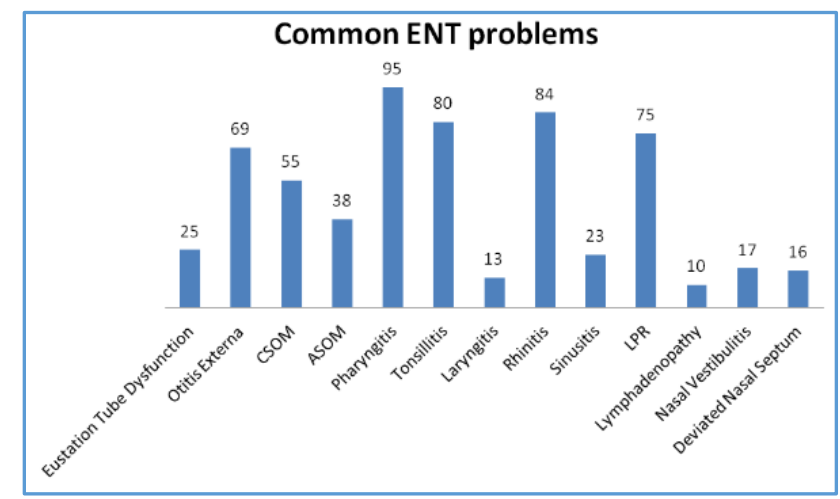

Graph 1. Graph showing the Occurrence of ENT Diseases in the Studied Population

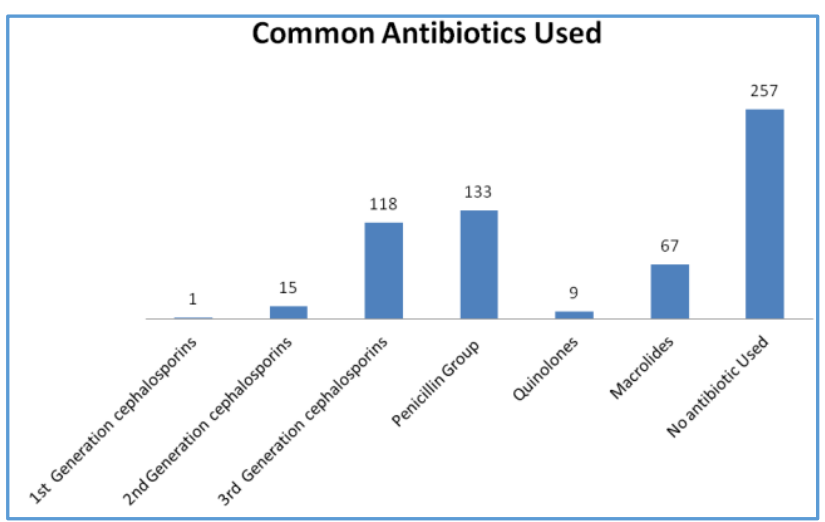

Graph 2. Graph showing the Use of Different Antibiotics for the ENT Diseases

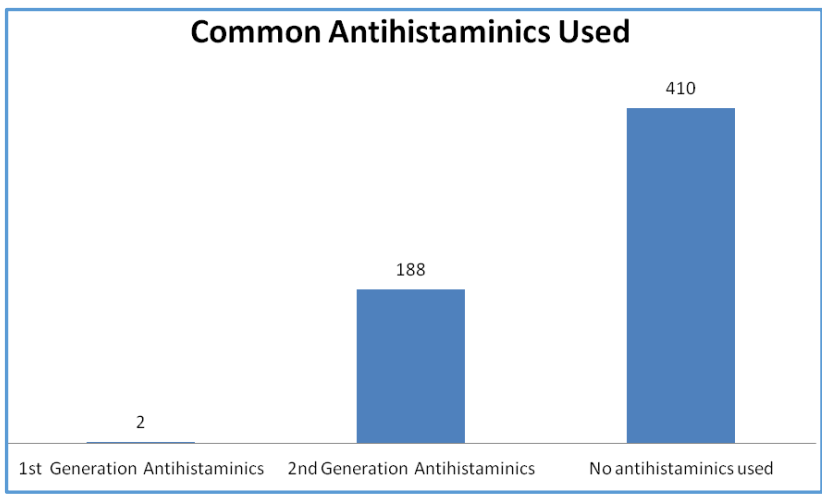

Graph 3. Graph showing the Use of Different Antihistaminics for the ENT Diseases

Graph 1 shows the frequency distribution of various ENT problems, we found that pharyngitis was the most common disease diagnosed which comprises of 95 cases followed by rhinitis 84, tonsillitis 80 and laryngopharyngeal reflux consists of 75 cases. Graph 2 shows the frequency distribution of various antibiotics used in the study population; 257 patients did not receive any antibiotic treatment and amongst the patients who received the antibiotics penicillin group is the most common antibiotic prescribed followed by third generation cephalosporin. Macrolide was the third common antibiotic group used. Graph 3 compared the frequency distribution of antihistaminics used where we see that second-generation non-sedative antihistamines were the most commonly prescribed group.

\begin{tabular}{|c|c|c|c|c|}
\hline \multicolumn{4}{|c|}{$\begin{array}{l}\text { Comparison of Duration of Symptoms with } \\
\text { Antibiotics used ( } p<0.05 \text { is significant) }\end{array}$} & \multirow{10}{*}{$\begin{array}{c}x^{2}=13.52 \\
d f=12, \\
p=0.332\end{array}$} \\
\hline & $\begin{array}{c}<1 \\
\text { Week }\end{array}$ & $\begin{array}{c}1-2 \\
\text { Weeks }\end{array}$ & $\begin{array}{c}>2 \\
\text { Weeks }\end{array}$ & \\
\hline $\begin{array}{c}1^{\text {st }} \text { Generation } \\
\text { cephalosporins }\end{array}$ & 1 & 0 & 0 & \\
\hline $\begin{array}{l}2^{\text {nd }} \text { Generation } \\
\text { cephalosporins }\end{array}$ & 12 & 1 & 2 & \\
\hline $\begin{array}{l}3^{\text {rd }} \text { Generation } \\
\text { cephalosporins }\end{array}$ & 77 & 29 & 12 & \\
\hline Penicillin Group & 97 & 21 & 15 & \\
\hline Quinolones & 7 & 0 & 2 & \\
\hline Macrolides & 45 & 13 & 9 & \\
\hline $\begin{array}{l}\text { No antibiotic } \\
\text { used }\end{array}$ & 157 & 55 & 45 & \\
\hline Total & 396 & 119 & 85 & \\
\hline
\end{tabular}

Table 2. Showing the Comparison of Duration of Symptoms with the Antibiotics given to the Studied Population 


\begin{tabular}{|c|c|c|c|c|c|c|c|c|c|}
\hline \multicolumn{9}{|c|}{ Comparison of Common ENT Problems with Antibiotics Used ( $p<0.05$ is significant) } & \multirow{17}{*}{$\begin{array}{c}\mathrm{x}^{2}=3.21, \mathrm{df}=72, \\
\mathrm{p}=0.000^{*}\end{array}$} \\
\hline & \multicolumn{3}{|c|}{ Cephalosporin } & \multirow{2}{*}{$\begin{array}{l}\text { Penicillin } \\
\text { Group }\end{array}$} & \multirow{2}{*}{ Quinolones } & \multirow{2}{*}{ Macrolides } & \multirow{2}{*}{ Not Given } & \multirow{2}{*}{ Total } & \\
\hline & 1st Gen & 2nd Gen & 3rd Gen & & & & & & \\
\hline $\begin{array}{c}\text { Eustachian Tube } \\
\text { Dysfunction }\end{array}$ & 0 & 0 & 4 & 3 & 0 & 2 & 16 & 25 & \\
\hline Otitis Externa & 0 & 0 & 17 & 19 & 1 & 3 & 29 & 69 & \\
\hline CSOM & 0 & 4 & 16 & 14 & 2 & 1 & 18 & 55 & \\
\hline ASOM & 0 & 0 & 9 & 21 & 1 & 2 & 5 & 38 & \\
\hline Pharyngitis & 1 & 0 & 19 & 17 & 1 & 29 & 28 & 95 & \\
\hline Tonsillitis & 0 & 4 & 25 & 31 & 0 & 4 & 16 & 80 & \\
\hline Laryngitis & 0 & 3 & 3 & 0 & 0 & 0 & 7 & 13 & \\
\hline Rhinitis & 0 & 3 & 3 & 6 & 2 & 6 & 64 & 84 & \\
\hline Sinusitis & 0 & 0 & 10 & 1 & 0 & 9 & 3 & 23 & \\
\hline LPR & 0 & 0 & 3 & 1 & 1 & 8 & 62 & 75 & \\
\hline Lymphadenopathy & 0 & 1 & 2 & 5 & 0 & 1 & 1 & 10 & \\
\hline Nasal Vestibulitis & 0 & 0 & 4 & 11 & 1 & 1 & 0 & 17 & \\
\hline $\begin{array}{c}\text { Deviated Nasal } \\
\text { Septum }\end{array}$ & 0 & 0 & 3 & 4 & 0 & 1 & 8 & 16 & \\
\hline Total & 1 & 15 & 118 & 133 & 9 & 67 & 257 & 600 & \\
\hline
\end{tabular}

Table 2 and 3 shows the comparison of antibiotics given with duration of symptoms of ENT disease respectively. Comparison of antibiotic use with duration of diseases shows that there is no significant relationship between the two entities of the table $(p=0.332)$. On comparison of antibiotic use with ENT diseases tells that their relation is of high significance, that is the prescription of the antibiotic is dependent on respective ENT disease.

\begin{tabular}{|c|c|c|c|c|}
\hline \multicolumn{6}{|c|}{ Comparison of Duration of Symptoms with } \\
Antihistamines Drugs Used (p < 0.05 is significant)
\end{tabular}

Table 4. Showing the Comparison of Duration of Symptoms with the Antihistamines given to the Studied Population

\begin{tabular}{|c|c|c|c|c|c|}
\hline \multicolumn{5}{|c|}{ Comparison of Common ENT problems with Antihistamines Used ( $p<0.05$ is significant) } & \multirow{16}{*}{$\begin{array}{c}x^{2}=96.87, d f=24 \\
p=0.000^{*}\end{array}$} \\
\hline & $\begin{array}{c}\text { 1st Gen. } \\
\text { Antihistamine }\end{array}$ & $\begin{array}{c}\text { 2nd Gen. } \\
\text { Antihistamine }\end{array}$ & Not Given & Total & \\
\hline Eustachian Tube Dysfunction & 0 & 16 & 9 & 25 & \\
\hline Otitis Externa & 0 & 9 & 60 & 69 & \\
\hline CSOM & 0 & 24 & 31 & 55 & \\
\hline ASOM & 1 & 6 & 31 & 38 & \\
\hline Pharyngitis & 1 & 30 & 64 & 95 & \\
\hline Tonsillitis & 0 & 11 & 69 & 80 & \\
\hline Laryngitis & 0 & 1 & 12 & 13 & \\
\hline Rhinitis & 0 & 46 & 38 & 84 & \\
\hline Sinusitis & 0 & 7 & 16 & 23 & \\
\hline LPR & 0 & 35 & 40 & 75 & \\
\hline Lymphadenopathy & 0 & 0 & 10 & 10 & \\
\hline Nasal Vestibulitis & 0 & 1 & 16 & 17 & \\
\hline Deviated Nasal Septum & 0 & 2 & 14 & 16 & \\
\hline Total & 2 & 188 & 410 & 600 & \\
\hline
\end{tabular}

Table 4 and 5 shows the comparison of antihistamines given with duration of symptoms of ENT disease respectively. On comparison of antihistamine use with duration of diseases, it was found that there is no significant relationship between the two entities of the table as $p$ value is greater than $0.05(\mathrm{p}=0.762)$. On comparison of antihistamine use with ENT diseases tells that their relation is of high significance, that is the prescription of the antihistamine is also dependent on respective ENT disease. 


\begin{tabular}{|c|c|c|c|c|}
\hline \multicolumn{4}{|c|}{$\begin{array}{l}\text { Comparison of Duration of Symptoms with } \\
\text { Analgesics Used ( } p<0.05 \text { is significant) }\end{array}$} & \multirow{6}{*}{$\begin{array}{c}x^{2}=8.815, \\
d f=2, \\
p=0.012 *\end{array}$} \\
\hline & $\begin{array}{l}\text { Analgesic } \\
\text { Given }\end{array}$ & $\begin{array}{l}\text { Analgesic } \\
\text { Not Given }\end{array}$ & Total & \\
\hline$<1$ Week & 191 & 205 & 396 & \\
\hline 1 - 2 Weeks & 53 & 66 & 119 & \\
\hline$>2$ Weeks & 26 & 59 & 85 & \\
\hline Total & 270 & 330 & 600 & \\
\hline \multicolumn{5}{|c|}{$\begin{array}{l}\text { Table 6. Showing the Comparison of Duration of Symptoms } \\
\text { with the NSAIDs qiven to the Studied Population }\end{array}$} \\
\hline
\end{tabular}

\begin{tabular}{|c|c|c|c|c|}
\hline \multicolumn{4}{|c|}{$\begin{array}{c}\text { Comparison of Common ENT Problems with } \\
\text { Analgesics Used ( } p<0.05 \text { is significant) }\end{array}$} & \multirow{16}{*}{$\begin{array}{c}x^{2}= \\
90.088 \\
d f=12, p= \\
0.000^{*}\end{array}$} \\
\hline & $\begin{array}{c}\text { Analgesic } \\
\text { Given }\end{array}$ & $\begin{array}{l}\text { Analgesic } \\
\text { Not Given }\end{array}$ & Total & \\
\hline $\begin{array}{l}\text { Eustachian Tube } \\
\text { Dysfunction }\end{array}$ & 7 & 18 & 25 & \\
\hline Otitis Externa & 45 & 24 & 69 & \\
\hline CSOM & 17 & 38 & 55 & \\
\hline ASOM & 25 & 13 & 38 & \\
\hline Pharyngitis & 52 & 43 & 95 & \\
\hline Tonsillitis & 45 & 35 & 80 & \\
\hline Laryngitis & 3 & 10 & 13 & \\
\hline Rhinitis & 32 & 52 & 84 & \\
\hline Sinusitis & 7 & 16 & 23 & \\
\hline LPR & 7 & 68 & 75 & \\
\hline Lymphadenopathy & 7 & 3 & 10 & \\
\hline Nasal Vestibulitis & 10 & 7 & 17 & \\
\hline $\begin{array}{l}\text { Deviated Nasal } \\
\text { Septum }\end{array}$ & 13 & 3 & 16 & \\
\hline Total & 270 & 330 & 600 & \\
\hline
\end{tabular}

Table 6 and 7 shows the comparison of NSAIDs given with duration of symptoms and ENT disease respectively. On comparison of NSAIDs use with duration of diseases shows that there exists a significant relationship between the two entities of the table, as $\mathrm{p}$ value is less than 0.05 . Hence, the use of NSAIDs depend upon the duration of symptom. On comparison of NSAIDs use with ENT diseases reflects that their relation is of high significance, that is the prescription of the antibiotic is dependent on respective ENT disease.

\begin{tabular}{|c|c|c|c|c|}
\hline \multicolumn{4}{|c|}{$\begin{array}{l}\text { Comparison of Duration of Symptoms with } \\
\text { Decongestant Used ( } p<0.05 \text { is significant) }\end{array}$} & \multirow{6}{*}{$\begin{array}{c}x^{2}=5.496 \\
d f=2 \\
p=0.064\end{array}$} \\
\hline & $\begin{array}{l}\text { Decongestant } \\
\text { Given }\end{array}$ & $\begin{array}{c}\text { Decongestant } \\
\text { Not Given }\end{array}$ & Total & \\
\hline$<1$ Week & 130 & 266 & 396 & \\
\hline $\begin{array}{c}1-2 \\
\text { Weeks }\end{array}$ & 53 & 66 & 119 & \\
\hline$>2$ Weeks & 31 & 54 & 85 & \\
\hline Total & 214 & 386 & 600 & \\
\hline
\end{tabular}

\begin{tabular}{|c|c|c|c|c|}
\hline \multicolumn{4}{|c|}{$\begin{array}{c}\text { Comparison of Common ENT Problems with } \\
\text { Decongestants Used (p<0.05 is significant) }\end{array}$} & \\
\cline { 1 - 3 } & $\begin{array}{c}\text { Decongestant } \\
\text { Given }\end{array}$ & $\begin{array}{c}\text { Decongestant } \\
\text { Not Given }\end{array}$ & Total & \\
$\mathrm{x}^{2}=1.18$, \\
$\mathrm{df}=12$, \\
$\mathrm{p}=$ \\
$0 \begin{array}{c}\text { Eustachian } \\
\text { Tube } \\
\text { Dysfunction }\end{array}$ & 19 & 6 & 25 & \\
\hline Otitis Externa & 9 & 60 & 69 & \\
\cline { 1 - 4 } CSOM & 28 & 27 & 55 & \\
\hline ASOM & 24 & 14 & 38 & \\
\hline
\end{tabular}

\begin{tabular}{|c|c|c|c|}
\hline Pharyngitis & 18 & 77 & 95 \\
\hline Tonsillitis & 20 & 60 & 80 \\
\hline Laryngitis & 6 & 7 & 13 \\
\hline Rhinitis & 47 & 37 & 84 \\
\hline Sinusitis & 18 & 5 & 23 \\
\hline LPR & 11 & 64 & 75 \\
\hline $\begin{array}{c}\text { Lympha- } \\
\text { denopathy }\end{array}$ & 1 & 9 & 10 \\
\hline $\begin{array}{c}\text { Nasal } \\
\text { Vestibulitis }\end{array}$ & 6 & 11 & 17 \\
\hline $\begin{array}{c}\text { Deviated Nasal } \\
\text { Septum }\end{array}$ & 7 & 9 & 16 \\
\hline Total & 214 & 386 & 600 \\
\hline
\end{tabular}

Table 9. Showing the Comparison of ENT Diseases with the Decongestants given to the Studied Population

Table 8 and 9 shows the comparison of decongestants given with duration of symptoms and ENT disease respectively. On comparison of decongestants used with duration of diseases shows that there is no significant relationship between the two entities of the table, as $p$ value is greater than 0.05 . On comparison of decongestants used with ENT diseases tells that their relation is of high significance, that is the prescription of the decongestant is dependent on respective ENT disease.

\begin{tabular}{|c|c|c|c|c|}
\hline \multicolumn{4}{|c|}{\begin{tabular}{|c|} 
Comparison of Duration of Symptoms with \\
Proton Pump Inhibitor (PPI) Used ( $<<0.05$ is \\
significant)
\end{tabular}} & \multirow{6}{*}{$\begin{array}{c}x^{2}=7.674, \\
d f=2, \\
p=0.022 *\end{array}$} \\
\hline & $\begin{array}{c}\text { PPI } \\
\text { Given }\end{array}$ & PPI Not Given & Total & \\
\hline$<1$ Week & 160 & 236 & 396 & \\
\hline 1 - 2 Weeks & 34 & 85 & 119 & \\
\hline$>2$ Weeks & 25 & 60 & 85 & \\
\hline Total & 219 & 381 & 600 & \\
\hline
\end{tabular}

\begin{tabular}{|c|c|c|c|c|}
\hline \multicolumn{4}{|c|}{$\begin{array}{c}\text { Comparison of Common ENT Problems with } \\
\text { Proton Pump Inhibitor Used ( } p<0.05 \text { is } \\
\text { significant) }\end{array}$} & \multirow{16}{*}{$\begin{array}{l}x^{2}=1.84 \\
d f=12 \\
p=0.000^{*}\end{array}$} \\
\hline & \begin{tabular}{|c|} 
PPI \\
Given \\
\end{tabular} & \begin{tabular}{|c|}
$\begin{array}{c}\text { PPI Not } \\
\text { Given }\end{array}$ \\
\end{tabular} & Total & \\
\hline $\begin{array}{c}\text { Eustachian Tube } \\
\text { Dysfunction }\end{array}$ & 6 & 19 & 25 & \\
\hline Otitis Externa & 3 & 66 & 69 & \\
\hline $\mathrm{CSOM}$ & 8 & 47 & 55 & \\
\hline ASOM & 7 & 31 & 38 & \\
\hline Pharyngitis & 58 & 37 & 95 & \\
\hline Tonsillitis & 31 & 49 & 80 & \\
\hline Laryngitis & 5 & 8 & 13 & \\
\hline Rhinitis & 13 & 71 & 84 & \\
\hline Sinusitis & 10 & 13 & 23 & \\
\hline LPR & 66 & 9 & 75 & \\
\hline Lymphadenopathy & 6 & 4 & 10 & \\
\hline Nasal Vestibulitis & 4 & 13 & 17 & \\
\hline Deviated Nasal Septum & 2 & 14 & 16 & \\
\hline Total & 219 & 381 & 600 & \\
\hline
\end{tabular}

Table 10 and 11 shows the comparison of PPI given with duration of symptoms and ENT disease respectively. On comparison of PPI used with duration of diseases shows that there is a significant relationship between the two entities of the table as $p$ value is greater than 0.05 , i.e. then use of PPI is also dependent on the duration of symptom. On comparison 
of PPI use with ENT diseases tells that their relation is of high significance, that is the prescription of the PPI is also dependent on respective ENT disease.

\begin{tabular}{|c|c|c|c|c|}
\hline \multicolumn{4}{|c|}{$\begin{array}{l}\text { Comparison of Duration of Symptoms with } \\
\text { Steroids Used ( } p<0.05 \text { is significant) }\end{array}$} & \multirow{6}{*}{$\begin{array}{c}\mathrm{x}^{2}=12.38 \\
\mathrm{df}=2, \\
\mathrm{p}=0.002^{*}\end{array}$} \\
\hline & $\begin{array}{l}\text { Steroids } \\
\text { Given }\end{array}$ & $\begin{array}{c}\text { Steroids } \\
\text { Not Given }\end{array}$ & Total & \\
\hline$<1$ Week & 39 & 357 & 396 & \\
\hline 1 - 2 Weeks & 23 & 96 & 119 & \\
\hline$>2$ Weeks & 18 & 67 & 85 & \\
\hline Total & 80 & 520 & 600 & \\
\hline \multicolumn{5}{|c|}{$\begin{array}{l}\text { Table 12. Showing the Comparison of Duration of } \\
\text { Symptoms with the Steroids given to the Studied } \\
\text { Population }\end{array}$} \\
\hline
\end{tabular}

\begin{tabular}{|c|c|c|c|c|}
\hline \multicolumn{4}{|c|}{$\begin{array}{l}\text { Comparison of Common ENT Problems with } \\
\text { Steroids Used ( } p<0.05 \text { is significant) }\end{array}$} & \multirow{16}{*}{$\begin{array}{c}x^{2}=1.46, \\
d f=12, \\
p=0.000^{*}\end{array}$} \\
\hline & $\begin{array}{c}\text { Steroids } \\
\text { Given }\end{array}$ & $\begin{array}{c}\text { Steroids } \\
\text { Not Given }\end{array}$ & Total & \\
\hline $\begin{array}{l}\text { Eustachian Tube } \\
\text { Dysfunction }\end{array}$ & 1 & 24 & 25 & \\
\hline Otitis Externa & 1 & 68 & 69 & \\
\hline CSOM & 4 & 51 & 55 & \\
\hline ASOM & 0 & 38 & 38 & \\
\hline Pharyngitis & 2 & 93 & 95 & \\
\hline Tonsillitis & 16 & 64 & 80 & \\
\hline Laryngitis & 0 & 13 & 13 & \\
\hline Rhinitis & 42 & 42 & 84 & \\
\hline Sinusitis & 7 & 16 & 23 & \\
\hline LPR & 2 & 73 & 75 & \\
\hline Lymphadenopathy & 0 & 10 & 10 & \\
\hline Nasal Vestibulitis & 2 & 15 & 17 & \\
\hline $\begin{array}{l}\text { Deviated Nasal } \\
\text { Septum }\end{array}$ & 3 & 13 & 16 & \\
\hline Total & 80 & 520 & 600 & \\
\hline \multicolumn{5}{|c|}{$\begin{array}{c}\text { Table 13. Showing the Comparison of ENT Diseases with } \\
\text { the Steroids given to the Studied Population }\end{array}$} \\
\hline
\end{tabular}

Table 12 and 13 shows the comparison of steroids given with duration of symptoms and ENT disease respectively. On comparison of steroids use with duration of diseases shows that there is high significant relationship between the two entities of the table as $p$ value is less than 0.05 , i.e. then use of steroids is also dependent on the duration of symptom. On comparison of steroids use with ENT diseases tells that their relation is of high significance, that is the prescription of the steroid is also dependent on respective ENT disease.

\begin{tabular}{|c|c|c|c|c|}
\hline \multicolumn{4}{|c|}{$\begin{array}{c}\text { Comparison of Duration of Symptoms with } \\
\text { Multivitamins } \\
\text { Used ( } p<0.05 \text { is significant) }\end{array}$} & \multirow{6}{*}{$\begin{array}{c}x^{2}=1.053 \\
d f=2 \\
p=0.591\end{array}$} \\
\hline & $\begin{array}{c}\text { Multi- } \\
\text { vitamins } \\
\text { Given }\end{array}$ & $\begin{array}{c}\text { Multi- } \\
\text { vitamins } \\
\text { Not Given }\end{array}$ & Total & \\
\hline$<1$ Week & 31 & 365 & 396 & \\
\hline 1 - 2 Weeks & 8 & 11 & 19 & \\
\hline$>2$ Weeks & 9 & 76 & 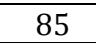 & \\
\hline Total & 48 & 552 & 600 & \\
\hline \multicolumn{5}{|c|}{$\begin{array}{c}\text { Table 14. Showing the Comparison of Duration of } \\
\text { Symptoms with the Multivitamins Given to the Studied } \\
\text { Population }\end{array}$} \\
\hline
\end{tabular}

\begin{tabular}{|c|c|c|c|c|}
\hline \multicolumn{4}{|c|}{\begin{tabular}{|l} 
Comparison of Common ENT Problems with \\
Multivitamins Used ( $p<0.05$ is significant) \\
\end{tabular}} & \multirow{16}{*}{$\begin{array}{c}\mathrm{x}^{2}=29.388, \\
\mathrm{df}=12, \\
\mathrm{p}=0.003^{*}\end{array}$} \\
\hline & $\begin{array}{c}\text { MVI } \\
\text { Given } \\
\end{array}$ & \begin{tabular}{|c|} 
MVI Not \\
Given
\end{tabular} & Total & \\
\hline $\begin{array}{l}\text { Eustachian Tube } \\
\text { Dysfunction }\end{array}$ & 2 & 23 & 25 & \\
\hline Otitis Externa & 1 & 68 & 69 & \\
\hline $\mathrm{CSOM}$ & 7 & 48 & 55 & \\
\hline ASOM & 1 & 37 & 38 & \\
\hline Pharyngitis & 18 & 77 & 95 & \\
\hline Tonsillitis & 8 & 72 & 80 & \\
\hline Laryngitis & 0 & 13 & 13 & \\
\hline Rhinitis & 6 & 78 & 84 & \\
\hline Sinusitis & 0 & 23 & 23 & \\
\hline LPR & 4 & 71 & 75 & \\
\hline Lymphadenopathy & 0 & 10 & 10 & \\
\hline Nasal Vestibulitis & 1 & 16 & 17 & \\
\hline $\begin{array}{c}\text { Deviated Nasal } \\
\text { Septum } \\
\end{array}$ & 0 & 16 & 16 & \\
\hline Total & 48 & 552 & 600 & \\
\hline
\end{tabular}

Table 14 and 15 shows the comparison of multivitamins given with duration of symptoms and ENT disease respectively. On comparison of multivitamins use with duration of diseases shows that there does not exist any significant relationship between the two entities of the table, as $\mathrm{p}$ value is greater than 0.05. On comparison of multivitamins use with ENT diseases tells that their relation is of high significance, that is the prescription of the multivitamins is also dependent on respective ENT disease.

\section{DISCUSSION}

Our study is a prospective cross-sectional study conducted in Department of ENT, Central Referral Hospital, Tadong, Gangtok, Sikkim; and STNM Hospital, Gangtok, Sikkim, done for a short period of two months where we studied 600 patients presenting to outpatient department of our hospital, of which 274 (45.7\%) were males and 326 (54.3) were females. A similar study was done by Padwal SL et al $(2015)^{6}$ on 855 patients, amongst which majority of them were males accounting for $59.64 \%$ which is in contrast to the present study. Another study was done by Sivakumar P et al $(2011)^{7}$ analysing the utilisation of antimicrobials in ENT patients, where 591 patients were studied of which 346 (59\%) were male and $245(41 \%)$ were female, which is again in contrast to our study group. The trends show more prevalence of ENT disease among female population of Sikkim than in comparison to their counterpart. Majority of the patients in our study are in the age group of 21 - 40 years, which accounted for $49.2 \%$ of the study population. This was similar to the results of a study done by Suman RK et al $(2014)^{8}$ in Navi Mumbai, India, in which 100 prescriptions were analysed and it was found that $56 \%$ prescriptions belonged to people in 21 - 30 years of age group. Similarly, another study done by Dhanasekharan SV et al $(2015)^{9}$ on 265 patients showed that majority of the study population were in the age group of 21 - 40 years. The reason behind the majority of the population belonging to this age group could be, because this population is ambulatory and occupational workers who come to the clinic to meet their health care needs. In the present study, majority of the study population 
is Hindu by religion accounting for $63.8 \%$ of the study population.

On comparing the site-specific complaint of the study population, we found that majority of them presented with throat complaint accounting for 218 (36.3\%) of the study population followed by 192 (32\%) with ear complaint, 120 (20\%) with nasal complaint and $70(11.7 \%)$ with other ENT complaints. In a similar study, analysing the use of antimicrobials in ENT Department carried out by Dhanasekharan SV et al (2015), ${ }^{9}$ it was seen that ear infections accounted for the majority (46\%) of the cases to visit ENT OPD followed by nasal and throat complaints $27 \%$ each. The reason behind ear infections being more common in their study could be because of a low socioeconomic status of the majority of the population, which accounted for the reduced health care delivery system. In our study majority of the population belonged to a middle-class family, who could afford the basic health care need and hence the difference. In our study, we also found that majority of patients (66\%) presented with acute symptoms, as the duration of the complaint was less than a week. The frequency distribution of the total study population is done, which shows that amongst various throat complaints pharyngitis $(15 \%)$ was the major complaint followed by rhinitis (14\%) and tonsillitis (13\%). Only $2 \%$ of patients complained of laryngitis. Amongst the ear complaint otitis externa was diagnosed in $69(12 \%)$ patients followed by CSOM in $55(9 \%)$ and ASOM in $38(6 \%)$ patients. Amongst the nasal complaints which were seen in only $20 \%$ of the study population, rhinitis was seen in 84 patients and sinusitis in 23 and amongst the other complaints laryngopharyngeal reflux was the major complaint noticed in 75 patients. A study done by Sivakumar P et al $(2011)^{7}$ showed that the major ear complaints were CSOM (37.89\%), amongst the nasal complaint acute rhinosinusitis was common (56.10\%) and amongst the throat complaints tonsillitis was seen in $65.11 \%$. In a similar study conducted by Any $\mathrm{OH}$ et al (2014) ${ }^{10}$, amongst the total of 150 patients, maximum cases were of otitis media 74 (49.33\%), sinusitis $24(16.00 \%)$, tonsillitis $15(10.00 \%)$, pharyngitis $14(9.33 \%)$, DNS 14 (9.33\%), rhinitis 7 (4.66\%) and adenoiditis 2 (1.33\%).

A total of 1614 drugs were prescribed in 600 prescriptions with an average of 2.69 drugs per prescription in our study, of which 257 (43\%) did not receive any antibiotics and 57\% received antibiotics for the various problems and $190(31.66 \%)$ patients received treatment with antihistamines. When we compared the total drugs prescribed in our study with another study, we ascertained that in a study conducted by Suman RK et al $(2014)^{8}$ a total of 314 drugs were prescribed in 100 prescriptions with an average of 3.14 drug per prescription. In another study by Padwal SL et al (2015), ${ }^{6}$ a total of 3342 drugs were prescribed through 855 prescriptions with an average of 3.90 drugs per prescription which is too high compared to our study. In this study ${ }^{6}$ antibiotics were prescribed in 831 (97.19\%) of the cases, which is again too high compared to our study and the prescription rate of antihistamines being too low as compared to ours (19.92\%). In a study done by Sivakumar P et al (2011), ${ }^{7}$ assessing utilisation of antimicrobial it was noticed that only 709 drugs were prescribed for 591 prescriptions with an average of $1.20 \mathrm{drug}$ per prescription being lesser as compared to ours. The study highlights the lesser use of antimicrobials for the common diseases. However, the question which remains unanswered is 'what is the average number of drugs to be prescribed per prescription to be effective against all common infections encountered in ENT practices?' As none of the studies including the present study have been done at multiple centres, the results of these study cannot be generalised to the entire country and a large study covering multiple centres need to be undertaken to standardise the average amount of drugs per prescription to be prescribed.

When we analysed the patients receiving antibiotic treatment, we found that a total of 343 (57\%) members of the study population were treated with the antibiotic amongst which majority of them received treatment with Penicillin group of antibiotics accounting for $22.6 \%$ (133) of the total study population. The second most common antibiotic used in our study was a third-generation cephalosporin, of which majority received treatment with cefpodoxime proxetil given to $118(19.6 \%)$ patients. The other common antibiotics used was a group of macrolides prescribed to 67 (11.16\%) patients and fluoroquinolones prescribed only to 9 patients. All the antimicrobials were administered through oral route with no drugs given parenterally. When this pattern of utilisation of antimicrobials is compared with the other studies, we found that in a study conducted by Dhanasekharan SV et al $(2015)^{9}$ the commonest antibiotic prescribed was beta-lactams followed by aminoglycosides and fluoroquinolones. When this data of commonest antibiotics is juxtaposed with this study it is concluded that in their study the commonest drug was beta-lactam, hence reflecting the similar results. Another study done by Ain MR et al $(2010)^{11}$ also showed beta-lactam $(45.52 \%)$ to be the most common antimicrobial drug prescribed followed by quinolones $(26.31 \%)$; however, the use of quinolones is not seen commonly in our study which differs from the above two studies. Amongst the third-generation cephalosporin in a study by Ain MR et al (2010),11 use of cefpodoxime proxetil is noticed which is similar to our study. A study done by Sivakumar P et al $(2015)^{7}$ differ from our study, where they used Fluoroquinolones in $61.88 \%$ of their cases. The reason behind the high prescription rate of third generation cephalosporin in our group may be that the majority of the study sample came to private hospital setup with a maximum of them belonging to middle class, to the upper-class family. We also studied the use of antihistamines where we saw that a total of 190 (31.66\%) patients received treatment with these drugs, of which majority received treatment with second generation (non-sedative) antihistamines.

We also try to justify the use of various drugs in the treatment of various ENT diseases (Table 3) in terms of duration of symptoms (Table 2) and use of medications, where it is found that use of antibiotics has no significant relation with the duration of symptom ( $p$-value being more than 0.05 which is not significant) reflecting that the use of antibiotics depends on the sensitivity of the infecting organism rather than on the duration of symptom. However, on comparing the use of various antibiotics with the different ENT problems, the analysis showed p-value less than 0.05 , which is significant indicating that majority of the ENT problems for which the antibiotics were prescribed is actually needed for the respective problems and this 
indication is not just a chance but is because of actual microbial infection and thus the use of antibiotics is justified.

In Table 4 and Table 5, we are trying to relate the use of antihistamines in terms of duration of symptoms and the common ENT disease, where we see that the use of antihistamines should not be decided in terms of duration of symptoms as the p-value was more than 0.05 which is not significant, rather the use of the drug should be decided on the type of ENT disease as majority of the patients in our population were suffering from tubal dysfunction and allergic rhinitis, hence rationalising the treatment.

In Table 6 and Table 7, an attempt is made to rationale the use of non-steroidal anti-inflammatory drugs in terms of duration of symptoms and the various ENT diseases where we see that the indication of NSAIDs use depends on duration of inflammation, $p$-value is 0.012 which is highly significant and also the use of NSAIDS in various ENT conditions helps in quick healing of these problems as indicated by the $\mathrm{p}$ value of 0.000 which is highly significant.

In Table 8 we try to explain the use of decongestants in terms of duration of symptoms where we see that the use of decongestant is independent of the duration of symptom, rather it is dependent on the condition (Table 9), which the patient is suffering from as indicated by their respective $p$ value.

In Table 10 and Table 11, we try to justify the use of Proton Pump Inhibitor (PPI) in terms of duration and various ENT problems, where we see that the use of this medication is indicated in terms of duration of symptoms as the longer the duration of symptoms the more is the stress reaction. The $\mathrm{p}$-value for this is 0.022 , which is highly significant. When we compare the use of PPI in various ENT problems, the p-value is 0.000 which is highly significant.

Table 12 and Table 13 tries to rationale the use of steroids in terms of duration and ENT problems. We see that longer the duration of symptoms more is the inflammation and thus the use of steroids is justified as the p-value is 0.002 which is highly significant. When we see the other table where we compare use of steroids with various ENT problems, we found p-value to be 0.000 which is highly significant. Also, when we see the disease pattern where steroids were given, we found allergic rhinitis was the most common disease where steroid was given and as the disease is chronic hence the treatment is justified.

Table 14 shows the comparison of the use of multivitamin with duration of symptoms where the $\mathrm{p}$-value is 0.591 which is not significant, hence the use of a multivitamin in terms of duration of symptoms is not rationalised. However, the use of multivitamin for various ENT problems is justified as the $\mathrm{P}$ value is 0.003 , which is highly significant.

\section{CONCLUSION}

In our study, prescriptions for 600 patients have been worked out where an occurrence of the common ENT diseases and their treatment pattern has been analysed. According to the results formulated, it is seen that the use of the third-generation cephalosporin is more frequent as compared to fluoroquinolones, which are one of the commonest prescribed drugs as seen in other studies. This may be due to the socioeconomic status of the patients, as most of them belong to upper to middle class and can easily afford the prescribed drug.
It is also noticed that in our study the average number of drugs prescribed is 2.69 drugs per prescription, which differ from the studies referred. Some of them have an average of 1 , while others have an average of 4 drugs prescribed per prescription. So, to standardise the pattern of prescription for the common ENT diseases, such studies should be conducted on the large scale throughout the country.

The present study also shows overuse of brand name over the generic name, while prescribing medicines which increases the cost per prescription.

The patients studied are very low and the study is restricted to two hospitals, hence the result cannot be generalised for the whole country.

Standard treatment guidelines, hospital formulary and educational intervention become essential to modify this behaviour to benefit the patient.

\section{Summary}

- Sample size is fairly large as compared to similar studies under identical settings.

- The present study is first of its kind when geographical location is considered (Hilly, smallest North-Eastern state of India).

- Existing literature shows a wide range of number of drugs (1 - 4) per prescription for common ENT diseases. The present study reflects an average of 2.69 drugs per prescription, which is neither low nor high.

- The study shows that Beta-lactam and Cephalosporins were the most prescribed group. Other studies show Beta-lactam, aminoglycosides and Quinolones as the most prescribed group.

- None of the past studies compared drugs used with duration of illness and types of common ENT diseases.

\section{REFERENCES}

[1] Shalini S, Ravichandran V, Mohanty BK, et al. Drug utilization studies-an overview. International Journal of Pharmaceutical Sciences and Nanotechnology 2010;3(1):803-10.

[2] Gama H. Drug utilization studies. Arquil Med 2008;22(2-3):69-74.

[3] Khan AF, Nizamuddin S, Salman MT. Pattern of prescription of antimicrobial agents in the department of otorhinolaryngology in a tertiary care teaching hospital. African Journal of Pharmacy and Pharmacology 2011;5(14):1732-8.

[4] Yadav P, Kanase V, Lacchiramka P, et al. Drug utilization trend in the ENT out patient department in a teaching hospital. International Journal of Pharma and Bio Sciences 2010;1(4):153-60.

[5] Remesh A, Salim S, Gayathri MA, et al. Antibiotic prescribing pattern in the in-patient departments of a tertiary care hospital. Archives of Pharmacy Practice 2013;4(2):71-6.

[6] Padwal SL, Kulkarni MD, Deshmukh VS, et al. Drug use pattern in the ear, nose, throat outpatient department of a rural tertiary-care teaching hospital. Natl J Physiol Pharm Pharmacol 2015;5(3):212-6.

[7] Sivakumar P, Razak TA, Perumal P. Drug utilization of antimicrobials in ENT patients. Asian Journal of Pharmaceutical and Clinical Research 2011;4(1):1235. 
[8] Suman RK, Kumar R, Garje YA, et al. Drug usage patterns in ENT out patients department of teaching hospital. International Journal of Scientific Research 2014;3(7):341-3.

[9] Dhanasekharan SV, Rajaram S, Jayan M, et al. Trends of antimicrobial prescription in department of otorhinolaryngology in a teritiary care teaching hospital. Medico Research Chronicles 2015;2(1):4450.
[10] Any OH, Banu LA, Sultana R, et al. Drug utilization trends in ENT out patient department in a private teaching hospital in Bangladesh. Bangladesh J Physiol Pharmacol 2014;30(2):41-5.

[11] Ain MR, Shahzad N, Aqil M, et al. Drug utilization pattern of antibacterials used in ear, nose and throat outpatient and inpatient departments of a university hospital at New Delhi, India. J Pharm Bioallied Sci 2010;2(1):8-12. 